\title{
Condiciones de trabajo en la industria maquiladora de tipo electrónico. El caso de Ciudad Juárez
}

\author{
Lilia Venegas Aguilera \\ Instituto Nacional de Antropología e Historia \\ Dalia Barrera Bassols \\ Escuela Nacional de Antropología e Historia
}

\begin{abstract}
Resumen
Este trabajo es un avance de la investigación emprendida en el año de 1981 realizada en torno a las condiciones de vida y de trabajo en la industria maquiladora. Para ello se eligió a Ciudad Juárez, que para 1982 contaba ya con 42,695 trabajadores en este tipo de industria. En primer lugar se presenta la importancia y características de esta industria, particularmente de tipo electrónico, y dentro de este marco referencial se aborda el análisis de las condiciones laborales de las trabajadoras de esta rama industrial que representaban el $67 \%$ del total de trabajadores de maquiladoras de esa ciudad fronteriza. La fuente de información proviene de una encuesta aplicada en 28 empresas, el 57\% de las existentes y alrededor de 162 obreras.
\end{abstract}

Palabras clave: maquiladoras electrónicas, mano de obra fronteriza, devaluación, discriminación, explotación.

\begin{abstract}
This essay offers an advance of a research that started on 1981 about life and working conditions in the maquila industry. For this research, Ciudad Juárez was chose, which by 1982 already had 42,695 workers in this kind of industry. First, it presents the importance and characteristics of electronic industry, and taking this as a reference, it discusses the analysis of the working conditions of working women. This industrial group represented $67 \%$ from the total maquila workers of that border city. The source for this information comes from a survey applied to 28 companies, 57\% of the total existing factories, consisting on 162 working women in these industrial centers.
\end{abstract}

Keywords: electronic maquila factories, border labor power, devaluation, discrimination, exploitation. 


\title{
CONDICIONES DE TRABAJO EN LA INDUSTRIA MAQUILADORA DE TIPO ELECTRONICO. EL CASO DE CIUDAD JUAREZ
}

\author{
Por
}

Lilia Venegas Aguilera*

Dalia Barrera Bassols **

\section{INTRODUCCION}

El movimiento obrero, como hecho social fundamental y complejo, presenta para su análisis múltiples aspectos. Y eso no sólo porque en sí mismo es algo que abarca varios niveles de la realidad -desde el nivel económico, hasta el nivel incluso cotidiano y personal, pasando por su formas políticas y sociales- sino también porque se inserta, en sus diversos grados de desarrollo y en sus variadas formas de existencia, en la línea central de evolución de toda sociedad actual.

Por tanto, hablar de movimiento obrero es hablar de un amplio abanico de enfoques y perspectivas, de un vasto conjunto de temas, en torno de la clase social más importante, en la actualidad, en el mundo moderno.

De este amplio abanico, un aspecto que tiene especial relevancia es el que nos remite a una de las bases materiales que estructuran y definen, si bien sólo parcialmente, el caracter global de ese movimiento: el problema de las condiciones de trabajo. ${ }^{1}$

Las condiciones de trabajo delimitan, en primera instancia, la peculiaridad o singularidad de los procesos de trabajo, aquello que los hace procesos laborales concretos y diferenciales entre sí. Por tanto, constituyen un punto de partida importante para las demandas específicas que el sector o grupo de la clase obrera inserto en cada proceso de trabajo diferencial, reivindica frente a "sus" particulares capitalistas.

De ahí la importancia de su conocimiento. Pero tambien de ahí, su limitación inmanente: si la clase obrera se organiza, en una fase dada de su desarrollo, como movimiento obrero independiente en el plano nacional, no lo hace en función de sus diferencias concretas, sino a partir de sus rasgos

* Investigadora del Instituto de Nacional de Antropología e Historia.

** Profesora de la Escuela Nacional de Antropología e Historia.

1 Dejando de lado por ahora, la discusión respecto al contenido preciso de este concepto, aclaramos que nosotros lo concebimos en este texto en cuanto a su sentido restringido, como un conjunto de condiciones inmediatas del proceso de trabajo mismo, tales como el ritmo e intensidad del trabajo, duación y carácter de la jornada laboral, ambiente laboral, condiciones de seguridad e higiene, etc. 
generales, de sus determinaciones como "obrero en tanto tal", condiciones idénticas para todos sus miembros, igualmente sometidos al dominio y a la explotación del capital.

Por tanto, si hablamos de condiciones de trabajo de una industria específica, hablamos de movimiento obrero en una particular fase de su desarrollo, aludiendo centralmente sólo a ciertos aspectos de su forma de existencia.

Pero de la misma manera que lo general no existe más que como invarianza esencial de los muchos casos de lo particular, un movimiento obrero nacional no surge sino como síntesis y fusión de varias corrientes obreras locales o sectoriales previas. Y en la aceleración de este paso, un aporte posible lo constituye precisamente el conocimiento más cercano y preciso de las peculiaridades y determinaciones concretas, de las condiciones de trabajo de la clase obrera, en las distintas ramas e industriaas de nuestro país.

Pasemos entonces a la consideración de nuestro objeto de análisis: el desglose detallado de algunas de las más importantes condiciones de trabajo de las obreras, en las industrias maquiladoras de tipo electrónico, en Ciudad Juárez, Chihuahua. Para esto, ubicaremos primero muy brevemente la importancia y características de la industria maquiladora electrónica, dentro del país y más específicamente en el caso de Ciudad Juárez, para sobre esta base, entrar entonces de lleno al abordaje de las condiciones laborales de las trabajadoras en esta industria particular.

\section{LA INDUSTRIA MAQUILADORA EN CIUDAD JUAREZ}

El panorama de la industria maquiladora en la región fronteriza norte de nuestro país ha seguido un curso creciente, a pesar de los altibajos que, a través de casi 20 años, se han presentado.

Cuando en 1975-76 ocurrió la primera crisis de este tipo de industrias, se puso en cuestión incluso la posibilidad de su permanencia en el país, de ahí el sobrenombre de "industrias golondrina", o "run away industries", debido a la rapidez con que aparecían y dejaban de existir. En el ánimo de los habitantes fronterizos se creó una especie de temor a que la huida de las maquiladoras podía ocurrir en cualquier momento.

Hacia 1981, poco antes de la devaluación, los anuncios de "no vacantes" se encontraban en casi todas las plantas de Ciudad Juárez, ocurriendo una ola de despidos masivos. No obstante, la devaluación de 1982 abarató la fuerza de trabajo mexicana, desde el punto de vista de estas empresas transnacionales, las cuales vieron aumentar las "ventajas comparativas" de 
México para su funcionamiento. Actualmente, hay más maquiladoras en México que en Taiwán, Hong Kong o Corea. Del total de las maquiladoras norteamericanas, el $\mathbf{1 7 . 2 \%}$ se encuentran instaladas en la frontera norte de México, generando nuestro país el $76.4 \%$ del total de la producción de este tipo en Latinoamérica.

$\mathrm{La}$ industria maquiladora se ha convertido en la segunda fuente de divisas para México (después del petróleo), generando alrededor de 180,000 empleos que significan el $0.7 \%$ de la PEA nacional. Más del $90 \%$ de estas empresas se localizan en la franja fronteriza norte, distribuidas en 14 ciudades, de las cuales destacan Tijuana y Ciudad Juárez, con 124 y 129 plantas respectivamente, para 1982 .

El presente trabajo muestra un avance de la investigación que, en torno a las condiciones de vida y de trabajo en la industria maquiladora, emprendimos en el año de 1981. Para ello, elegimos a Ciudad Juárez, que para 1982 contaba ya con 42,695 trabajadores en este tipo de industrias, lo que representaba el $22 \%$ de su PEA. En esta ciudad funcionan actualmente tres parques industriales dedicados a la industria de maquila.

Sobre la base de los datos obtenidos acerca de las industrias maquiladoras operando en 1979 en esta ciudad, encontramos que el 43\% pertenecía a la rama electrónica, el $18 \%$ a la textil, y el resto cubría una amplia gama que va desde artículos de piel y de madera, hasta piñatas y adornos, o procesamiento de cupones. En 1979 las maquiladoras electrónicas ocupaban cerca de 28,500 empleados, es decir el 67\% del total de trabajadores de maquiladora en dicha ciudad. El levantamiento de datos para nuestro estudio se realizó en 1981 y, una mínima parte, en 1982, abarcando la aplicación de una encuesta relativa a las condiciones de vida y de trabajo a 162 obreras de maquila, 110 de las cuales trabajaban en una maquiladora de tipo electrónico.

Quedaron así representadas 28 empresas electrónicas, que significan el $57.14 \%$ de las 40 electrónicas censadas para fines de 1979 y el $79.88 \%$ de los empleados por ellas. La aplicación de las encuestas no pudo realizarse al interior de las fábricas, sino que debió efectuarse fuera de las horas de trabajo, esto debido a las múltiples reticiencias de las empresas respecto al estudio de las condiciones de trabajo que en ellas imperan. Además de las encuestas, se realizaron entrevistas abiertas a obreras de maquila, a diversos funcionarios del IMSS y otras dependencias oficiales, así como a líderes sindicales locales. 


\section{Características de la fuerza de trabajo y salarios}

A la inversa de lo que sucede en la industria a nivel nacional, en la cual más del $70 \%$ de los trabajadores son hombres, en la industria maquiladora cerca del $77 \%$ de los empleados son mujeres. Se ha hablado mucho acerca del porqué de este hecho. Se dice, por ejemplo, que las mujeres tienden a ser más responsables y más aptas que los hombres para los trabajos monótonos que requieren, además, minuciosidad. También se dice que las mujeres son más dóciles que los hombres. Hay que señalar, sin embargo, que los puestos que ellas ocupan en las empresas rara vez son puestos de mando, aunque los títulos de los puestos que ellas ocupan puedan aparentar lo contrario, Por lo general las mujeres son operadoras cuyo trabajo varía, evidentemente, dependiendo de la empresa que se trate. En la rama de las electrónicas las operadoras cubren una gama muy amplia de actividades, entre las que se cuentan ensamblaje, remaches, soldadoras, empaque, embobinado, etc. Las "operadoras especiales" surten de material a las líneas; la "supply", es la operadora "comodín", que entra en lugar de las obreras que van al baño, o que se ausentan del trabajo; las "jefas de línea" atienden los problemas de producción y calidad, ayudan a las que "se atrasan", y, en ocasiones, pasan "reportes de producción"; las "inspectoras de calidad" revisan la calidad del material que entra a la fábrica, así como la de los productos terminados. Estos "puestos especiales" son más bien técnicos, aunque en ocasiones involucran cierto grado de manejo personal. Sin embargo, no se trata de puestos que impliquen un amplio margen de toma de decisiones, ni tampoco una percepción económica sustantivamente superior a la del resto de las operadoras.

En la muestra se observa, por ejemplo, que cuando una operadora ganaba 5,880 pesos mensuales (1981), las operadoras especiales percibían entre 6,000 y 6,300 pesos en el mismo período. Las jefas de línea alcanzaban alrededor de 7,500 pesos y las inspectoras de calidad difícilmente ganaban 8,000 pesos. Esta estratificación al interior de la empresa no deja, sin embargo, de implicar diferencias ideológicas, y aun problemas entre las trabajadoras. $\mathrm{Al}$ ascender del puesto de simples operadoras algunas asumen una actitud más bien patronal, pero otras se quejan de que el sólo hecho de ser supervisoras, por ejemplo, hace que las operadoras les tengan cierta reticencia y rechazo para entablar una relación amistosa.

Las empresas electrónicas, por su tamaño y por lo sofisticado de su proceso de trabajo, son plantas que, en cierta forma, llevan la vanguardia en lo que se refiere a los conceptos de administración, división del trabajo y organización de éste. Así,no es raro encontrar todo un equipo de "apoyo a la producción", entre los que se cuentan: trabajadoras sociales, licenciados en relaciones industriales, jefes de capacitación, etc. Estos puestos, exceptuando a las trabajadoras sociales, se encuentran invariablemente, 
en manos de hombres, y cuando se trata de puestos de alta dirección, como la gerencia, lo más frecuente es que, además de ser hombres, sean también norteamericanos,

Las operadoras que trabajan en las maquiladoras de electrónica son, por lo general, muy jóvenes. En nuestra muestra el 58\% de ellas tenían menos de 25 años, y sólo un siete por ciento tenía más de 37 años. Más de la mitad eran solteras, aunque casi un catorce por ciento de ellas declararon ser "madres solteras". Los más altos grados de escolaridad se encontraron en esta rama, donde casi el $40 \%$ tenía estudios superiores a "secundariá incomleta" y algunas hasta "facultad incompleta".

Este primer acercamiento nos da una idea del perfil de las trabajadoras que se ocupan en las maquiladoras electrónicas: son mujeres jövenes, con una escolaridad promedio de primaria terminada, y con frecuencia con estudios superiores a ésta. Puede decirse que, en general, nacieron en Ciudad Juárez o en alguna otra ciudad del norte del país, lo que les da un cierto grado, bastante alto, de acercamiento a una "cultura citadina".

Por otro lado, su experiencia laboral previa a su ingreso en la maquiladora electrónica es, a grandes rasgos, como sigue: cerca del $67 \%$ de las trabajadoras encuestadas nunca habían trabajado en otra maquiladora. El $25 \%$ había trabajado en dos o tres maquiladoras, de las cuales por lo menos una pertenecía a la rama electrónica. El 37\% de las trabajadoras encuestadas no tenían experiencia laboral previa, se dedicaban al hogar, eran estudiantes o simplemente "desocupadas". El 18\% había trabajado como "sirvienta", "mesera" o "lavaplatos". Finalmente, un siete por ciento tenía como ocupación anterior la de "empleada comercial", "recepcionista", "cajera" o "maestra".

Como se señalaba anteriormente, la agudización de la crisis entre 1981 y 1982 favoreció la apertura de nuevas plantas de maquiladoras, y con ellas la creación de nuevos empleos en este tipo de industrias. No obstante, este fenómeno no se tradujo, como es fácil suponer, en una situación de bonanza para las ciudades fronterizas, entre ellas Ciudad Juárez; por el contrario, llegó a declararse "zona de desastre" debido a las repercusiones que la devaluación, el control de cambios y la inflación acarrearon para la población juarense. Según declaraciones de funcionarios públicos a la prensa, la dependencia del comercio de Ciudad Juárez respecto a El Paso llegaba, algunos años antes de la devaluación, a cerca del $80 \%$.

Evidentemente esta difícil situación afectó a toda la población fronteriza, pero como ocurre en todo el país, fue la clase trabajadora la que más resintió esta crisis. El poder adquisitivo de las obreras de la maquila, que 
se había venido deteriorando crónicamente desde años atrás, sufrió entonces una grave caída. De agosto de 1980 a 1981 el índice de inflación aumentó en un $18.7 \%$, tres puntos más abajo que la inflación en la zona metropolitana del D.F.; pero de agosto de 1981 al mismo mes en 1982 el índice de incremento de precios llegó en Ciudad Juárez al $87.7 \%$, cuando en el D.F. alcanzaba un orden de incremento del $65.8 \%$.

Los salarios mínimos en Ciudad Juárez aumentaron, entre 1981 y 1982 , en un $85.7 \%$; a primera vista puede parecer que el aumento de salarios niveló el aumento de precios. Hay que observar, sin embargo, que el dato reseñado del aumento de precios abarcó los aumentos hasta agosto de 1982, pero fue en septiembre de ese año cuando la crisis se acentuó, principalmente con la devaluación del primero de septiembre y con la decisión presidencial del control de cambios. Las condiciones de vida de las obreras, como es de imaginarse, se deterioraron sustancialmente.

Puede decirse que por regla general las maquiladoras electrónicas parecerían respetar los salarios establecidos por la Comisión Nacional de Salarios Mínimos, pero en nuestra muestra las obreras entrevistadas en 1981 afirmaron recibir 5,888 pesos mensuales, cuando el salario mínimo vigente era de 6,300 pesos. Esto puede deberse a que se realizaba algún tipo de descuento, pero hay que recordar que el salario mínimo no es gravable, to que hace necesario estudiar este punto más a fondo.

Según datos de un estudio realizado por la CTM y la CROC locales, este salario se distribuía de la siguiente manera: $31 \%$ en pago de alquiler de la vivienda, $40 \%$ en alimentación, $12.8 \%$ en transporte, $11.3 \%$ en vestido y telas, $8 \%$ en calzado y $6.9 \%$ en educación y otros gastos.

En tanto que del total de empresas maquiladoras sólo un 33\% cuenta con sindicatos, controlados por la CTM, la CROC y la CRT, la defensa de las condiciones de vida de las trabajadoras va siempre a la zaga de sus necesidades reales. Las demandas por incrementos salariales, y aun los emplazamientos a huelga por esta causa, son siempre los que dictan las centrales obreras del D.F., y se atenúan más en Ciudad Juárez, por la amenaza, velada o explícita, de la posible huida de las empresas maquiladoras. Los dirigentes sindicales son incluso los primeros en pedir "moderación" a sus agremiados.

\section{Contratación}

En el período comprendido entre 1981 y 1983 ocurrieron cambios económicos muy profundos, a causa de la devaluación, la agudización de la crisis en México, el control de cambios, etc. En términos de la creación de 
empleos, puede decirse que, paradójicamente, para la industria maquiladora se trató de un período de auge. En este tiempo se instalaron muchas empresas nuevas, se creó el tercer parque industrial de Ciudad Juárez, y los anuncios de vacantes en los periódicos aumentaron sustancialmente. Inusitadamente, incluso, los anuncios en los diarios parecían no bastar, por lo que camionetas con altavoces recorrían las colonias populares, invitando a las jóvenes a acudir a las fábricas a solicitar empleo.

La prensa local dedicaba el año pasado varios artículos llamando la atención sobbre este hecho, externando opiniones muy variadas al respecto. En algunos se comentaba que el problema de las maquiladoras en ese momento parecía ser el de la "escasez" de mano de obra: en otros, se aclaraba que no escaseaba la mano de obra, sino aquella que cumplía con los requisitos de contratación que las maquiladoras imponían.

En efecto, los requisitos para conitratación en estas plantas no son pocos. Estos, claro está, varían entre las distintas ramas, varían también entre las distintas empresas de la misma rama, e incluso varían dentro de la misma empresa en diferentes periodos aun cuando se trata de contratar para el puesto de "operadora".

En las electrónicas, lo más frecuente es que se exija la primaria completa, pero en ocasiones se pide también certificado de secundaria. Curiosamente, los requisitos no sólo exigen un mínimo de escolaridad, sino que en estas plantas es frecuente la fijación de un máximo de estudios, de preparatoria, para el puesto de operadora.

Al lado de los requisitos de escolaridad se piden cartas de recomendación, examen médico, prueba de habilidades y, en ocasiones, experiencia previa. Además de hacerse explícito el máximo de edad, es sabido entre las solicitantes que las empresas siempre seleccionan a las más jóvenes. Esto es especialmente cierto para las empresas electrónicas, y más flexible para las de la confección.

Los requisitos mencionados implican una serie de presiones que funcionan en pro del desarrollo armónico de la industria maquiladora en general, y también en pro de los ahorros de las empresas en particular: la carta de recomendación sólo se consigue si no se han presentado demandas en contra de alguna empresa frente a Conciliación y Arbitraje; si se ha participado en la formación de sindicato no deseado por la empresa, la carta de recomendación también puede ser negada. El examen médico incluye una prueba de que la solicitante no se encuentra embarazada en el momento de la contratación, lo cual haría a las empresas, "conceder" a corto plazo, una serie de prestaciones, y supondría una baja en la "productividad", se planteaba 
en el diario El Fronterizo que los embarazos hacían reducir la producción en las industrias de maquila por lo menos en un $5 \%$ anual. De ahí los esfuerzos del IMSS, en sus campañas de "planificación familiar", al interior de las empresas de maquila).

Otra de las exigencias de algunas empresas consiste en pedir a las solicitantes la disponibilidad de aceptar turnos rotativos. Esto reduce el número de trabajadoras aceptables para las plantas, ya que muchas mujeres no pueden aceptar esta situación laboral, que afecta profundamente la vida familiar de las trabajadoras. Cuando son muy jóvenes, consideran riesgoso el tener que permanecer en la planta cuando les toca el turno de noche; si son casadas o tienen hijos, los problemas que esto acarrea son aún mayores.

Haciendo a un lado las posibles diferencias derivadas del tipo de contratación posible (individual o colectiva, según se pertenezca o no a un sindicato), es sabido que existen una serie de artilugios legales que permiten a las empresas, en contra de lo establecido por la Ley Federal del Trabajo, despedir a las obreras en caso de comprobar que la empresa se encuentra en problemas económicos serios. Estos "recortes" de personal, aunados a las "huidas" de empresas ocurridas masivamente en tiempos de recesión en los E.E.U.U., nos hablan de una gran inestabilidad en el empleo en estas industrias.

De nuestra muestra, solamente el $34.51 \%$ de las obreras tenían "planta" en su empleo, en tanto que el $27.43 \%$ tenía más de 5 años de antigüedad en su empleo actual. Esto nos habla de la significativa rotación de personal que existe en estas empresas. Existirían dos posibilidades explicativas de este hecho, que quizás son complementarias. Por una parte, resulta obvio (y lo comprobaremos más adelante), que el alto ritmo de trábajo en las maquiladoras conlleva un desgaste brutal de la fuerza de trabajo, que hace "inútiles" a las obreras en muy corto tiempo, menor aún del de la media nacional. Por otra parte, existen abundantes elementos que hablan de la llamada "crisis del taylorismo", que produce como respuesta obrera el ausentismo, el turn-over incrementado, etc. Quizás los elementos vertidos en el resto de este trabajo contribuyan a aclarar este punto más abundantemente.

\section{Horario de la jornada laboral}

En este rubro, la industria maquiladora de tipo electrónico, no parece presentar ninguna peculiaridad especial. La jornada laboral es de 48 horas semanales -como en gran parte de la industria nacional- sin tomar en cuenta las horas extras trabajadas, que son muy variables. Estas 48 horas se cumplen muchas veces, mediante arreglos internos, de la siguiente manera: se trabaja en la semana durante nueve horas diarias y el sábado se completan las tres horas restantes. En algunas empresas existen dos y hasta 3 turnos, 
siendo todos ellos de entre ocho y nueve horas, inclusive el nocturno, lo que implica una clara violación a la Ley Federal del Trabajo.

Junto a esto, los lapsos o interrupciones de dicha jornada cotidiana son claramente insuficientes para reconstituir adecuadamente el desgaste de las obreras: hay dos interrupciones a lo largo del turno; una primera para tomar el desayuno o un refrigerio menor- cuya duración oscila entre 10 y 20 minutos-, y otra segunda para comer o tomar un alimento más completo -y cuya duración es de entre 25 y 30 minutos-. Si restamos a estos lapsos el tiempo que las obreras tardan en llegar al lugar donde se alimentan, y las características "trampas" que se realizan en el reloj checador ${ }^{2}$ (robándoles varios minutos), comprendemos que las enfermedades gastrointestinales ocupen un muy importante lugar entre este tipo de trabajadoras.

Cabe agregar que de todas las empresas encuestadas, ninguna cumplía con el tiempo marcado por la Ley Federal del Trabajo para permitir a las madres con hijos lactantes, su amamantamiento normal. Ya hemos visto que la "maternidad" es un rasgo non grato a los capitalistas de esta industria.

Como parte "complementaria" de la jornada laboral debemos incluir, en las circunstancias actuales, el tiempo de transporte desde la casa hasta la fábrica y viceversa.

\section{Tiempo de transporte}

Como resultado de nuestra encuesta registramos que el $50 \%$ de las obreras tardaba de 15 a 30 minutos en transportarse de su casa a su centro de trabajo; el $40 \%$ tardaba de 30 minutos a una hora, y el $10 \%$ tardaba más de una hora en llegar. En términos generales, las obreras de Ciudad Juárez se benefician del relativamente reducido tamaño de su urbe, lo que les permite que su tiempo de transporte no incremente demasiado su jornada laboral.

Pero lo que no pierden en tiempo lo pagan en incomodidad y dificultades en la transportación. Respecto al medio de transporte empleado, el $48.18 \%$ de las encuestadas viajaban en las famosas "ruteras" -similares a nuestras combis "peseras"- en donde se apeñuscan más de 25 obreras dentro de una camioneta cuyo cupo "oficial" es sólo de 14 . El $24.54 \%$ reportó viajar en camión, donde, igual que en la ciudad de México, a la clásica tar-

2 En el mes de agosto de 1980 , la J.C.A. emprendió una campaña de inspección de los relojes checadores de las maquiladoras, debido a las abundantes denuncias presentadas por las obreras. 
danza para pasar se suma el atiborramiento y el hecho de que los choferes ni siquiera paran para levantar al pasaje, especialmente en las "horas-pico". Por último, sólo un $20.9 \%$ reportó viajar en carro propio, mientras un $4.5 \%$ declaró hacerlo "en raite", pagándole, obviamente, la gasolina a la compañera dueña del carro. ${ }^{3}$

\section{Relaciones interpersonales al interior de la fábrica}

Dado el hecho de que las maquiladoras son empresas "intensivas de mano de obra" -lo que quiere decir que el trabajo vivo tiene un peso específico más alto que el promedio nacional-, lógico resulta que las relaciones personales, tanto entre las obreras mismas, como de las obreras con sus capataces -llámesele a éstos "supervisores", "jefes de línea", o como se quieracobren más importancia dentro de las condiciones de trabajc que en otras industrias o ramas económicas. Por tanto, el desarrollo de los métodos "tayloristas" y el afán por "humanizar las relaciones de trabajo", por mejorar "el ambiente laboral", etc., estarán a la orden del día, por parte de la empresa. Y consecuentemente suscitarán la respuesta o a veces, la insatisfacción de las trabajadoras.

Veamos cuál fue la opinión de las obreras encuestadas sobre este punto. A la pregunta de cómo juzgaban el trato de los capataces, se respondió del modo siguiente: en el $42.85 \%$ de los casos (o sea 12 empresas) no se respondió nada, lo que tal vez refleja la suspicacia de las trabajadoras, puesto que en estas empresas no se habla oficialmente de capataces, sino de supervisores. En las empresas en que sí se respondió (46.5\%), se afirmó que el trato era malo $(17.85 \%$, o sea cinco empresas) regular (también $17.85 \%$ ), y solamente que era bueno en 3 empresas (10.7\%). Esto demuestra claramente que, más allá de los esfuerzos patronales por encubrir y dulcificar las relaciones jerárquicas y despóticas al interior del proceso de trabajo, las obreras tienen clara conciencia de la explotación económica y de la sojuzgación política de que son víctimas.

Y esta conciencia se refleja ya claramente en las respuestas textuales de las obreras sobre esta cuestión. Sus respuestas fueron del siguiente tenor: "son muy desconsiderados con las empleadas", "no son respetuosos",

3 Los problemas causados a las empresas por la reducción de la productividad de sus obreras a causa de estas incomodidades han sido tales que, en mayo de 1983, un vocero de las empresas declaró que las limitaciones a su expansión radicaban en la insuficiencia de los servicios de teléfono y télex el deficiente transporte urbano, las interrupciones en la energía eléctrica, la insuficiente capacidad de sistemas de agua y drenaje y las "actividades" de grupos extremistas que causan disturbios e interrupciones en las fábricas. 
"a veces nos presionan mucho", "dan trato preferencial a sus amigas y molestan a las que les caen mal" y "nos tratan según como vean nuestro trabajo". ${ }^{4}$

El otro lado de esta relación jerárquica, entre capataces y obreras, se encuentra en la relación que las obreras mantienen entre sí. Aquí están presentes ciertos resabios de competitividad entre las trabajadoras y ciertas fricciones personales derivadas de las fuertes presiones patronales en torno a la productividad individual y a la "calidad" de la producción. Así, a la pregunta sobre el nivel del trato interobreras, la encuesta produjo las siguientes respuestas: en siete empresas (25\%) se calificó el trabajo de bueno, mientras que en 16 se calificó como regular $(64.28 \%)$. Sólo en cinco $(17.85 \%)$ se afirmó que era malo.

Interrogadas luego respecto a los motivos de que el trato entre ellas fuera considerado malo, o regular, se respondió del modo siguiente: se dijo que había obreras que promovían "envidias y chismes" sobre otras, que se debía a la "falta de compañerismo", a la "falta de comunicación" y a los "pleitos y malas palabras". Las obreras más avispadas tienen conciencia de que estos problemas dificultan la unidad y organización de su clase, por lo que tratan de combatirlos. En cambio los patrones, también claros del beneficio que les reporta la división entre sus empleadas, los fomentan e inducen abiertamente.

Así, tanto los supervisores como los jefes de línea, etc., auspician las acusaciones de unas obreras a otras, premiándolas; reparten el trabajo inequitativamente de acuerdo a sus preferencias personales, o dan cancha abierta a las reclamaciones de ciertas obreras a otras por "no haber cumplido el estándar", etc. Se oye entonces la queja de las trabajadoras: "no todas trabajamos igual", "a algunas les tocan trabajos más pesados que a otras", "entre las mismas trabajadoras, cuando no sacas el estándar, te llaman la atención".

De este modo se hace claro que la distribución y organización internas del trabajo, aunque obedecen principalmente a criterios técnicos, también son aprovechados como armas de tipo disciplinario y político, allí donde se

\footnotetext{
4 Un ejemplo de reacción de las obreras frente al mal trato de un capataz es el de Advance Ross, empresa que despidió injustificadamente a cinco obreras en mayo de 1971 , las cuales se dirigieron a la redacción del periódico local El Fronterizo para protestar: "Silvino Rodríguez, el capataz, es el que se encarga de hacer los despidos, como si él no se acordara de que fue pobre y que sólo está sirviendo de instrumento a los dueños de esa compañía para enriquecerlos".

Otra respuesta obrera a este tipo de situaciones es la de las obreras de Colicraft, que en julio de 1974 se dirigieron a la redacción de El Hronterizo, para denunciar el mal trato del jefe de personal hacia ellas con anuencia del sindicato "blanco" de la CROC, pidiendo se le cesara por "inepto y altanero".
} 
abre esta posibilidad, sea por parte de las propias trabajadoras, sea inducido por la empresa. ${ }^{5}$

\section{Condiciones de seguridad e higiene}

La imagen más difundida de las empresas maquiladoras fronterizas de la rama electrónica, es la de flamantes edificios nuevos, dentro de parques industriales exageradamente pulcros, con todos los servicios y con prados y árboles siempre estéticamente arreglados. A primera vista todo parece ser así. Sin embargo, en cuanto nos adentramos en el proceso productivo y escuchamos el punto de vista de las obreras directamente afectadas por éste, esta impresión da un giro radical. Vislumbramos entonces que también aquí -como en toda industria regida por criterios capitalistas-, la ęconomfa en el capital constante se realiza claramente a expensas de la salud, la higiene y la seguridad de los trabajadores, reafirmando una vez más que aquí "la producción existe para la producción misma" y no para los hombres.

Así, como resultado de la encuesta nos encontramos con que una tercera parte solamente de las empresas registradas, fue considerada como de edificio nuevo, mientras las dos terceras partes restantes se clasificaban como seminuevos -recuérdese a este respecto que la industria maquiladora sólo data de 1965- Pero en cambio, al inquirir sobre la limpieza de dichos edificios, sólo la cuarta parte se concibieron como limpios, mientras las tres cuartas partes restantes eran calificados como de limpieza "regular". Se encontraron quejas sobre goteras, sobre gran cantidad de ratas y sobre amontonamiento de los equipos y falta de espacio en algunas de las empresas, lo que nos recuerda nuevamente que el capital no es precisamente derrochador en lo que a condiciones de trabajo se refiere.

Los sanitarios resultaron ser fuente de muchos problemas, siendo considerados, en casi una tercera parte de las empresas encuestadas, como limpios, pero sucios en la mitad de las empresas, mientras en el resto se les calificó de regulares, Las quejas aquí coíncidían en la falta de aseo, de jabón y de papel higiénico, así como de que frecuentemente se descomponían o faltaba el agua.

Respecto al comedor de la empresa, en poco más de la mitad de las empresas fue considerado limpio; en una tercera parte, regular, y en el resto, sucio. Las quejas sobre el comedor, en 16 de las empresas (57:14\%), se centraron en lo antihigiénica y la mala calidad de la comida y, sobre todo,

\footnotetext{
5 Un ejemplo de esto lo tenemos en la maquiladora RCA, en la cual las obreras, en franca actitud de descontento hacia su sindicato de la CTM, denunciaron en El Fronterizo la corrupción de su líder, así como la serie de presiones sobre los trabajadores inconformes, ejercidas por los jefes de la línea, "atemorizándolos con posibles reportes sobre disciplina y retardo en la producción".
} 
en lo cara que resultaba. En cinco de las empresas (17.85\%), se consideró insuficiente el local del comedor, por lo que las comidas debían tomarse en diferentes turnos, ocasionando problemas y aglomeraciones.

En la tercera parte de las empresas, el aire acondicionado y la calefacción, muy necesarios dadas las características climáticas de Ciudad Juárez, fueron considerados satisfactorios en todos los turnos de trabajo, y a lo largo de todo el año. En las dos terceras partes restantes fueron considerados insuficientes. Quizás debido a las necesidades de la producción, en una de las empresas se quejaron de que "prenden el aire cuando hace frío y no cuando hace calor".

Dentro de este rubro, serían de considerarse las medidas para prevenir y controlar la contaminación y para la ventilación del local de trabajo. Aunque esta pregunta no se formuló en el cuestionario, las quejas coincidieron a este respecto en el excesivo calor despedido por las máquinas y no contrarrestado suficientemente por el aire acondicionado, los olores, el aire viciado "que asfixia y ataranta", que "no hay aire natural", e inclusive que no existían ventanas, y finalmente, que el humo de la soldadura y los gases y substancias empleadas enrarecían el ambiente, irritando ojos y nariz.

Como vemos, no es la seguridad, comodidad o higiene de las obreras que lo que "les quita el sueño" a los dueños de las maquiladoras. (Todo gasto en estos rubros que rebase el "mínimo indispensable" requerido técnicamente -y a veces aún menos-, es considerado un "gasto falso" de la producción, y por tanto reducido lo más posible). Pero continuemos.

El alumbrado, aunque se trataba en la mayoría de los casos de alumbrado artificial y no natural, fue considerado bueno en las dos terceras partes de las empresas registradas. En la otra tercera parte era en cambio regular o malo. Esto se explica muy posiblemente por el hecho de que una buena visión es imprescindible en la mayoría de los procesos de trabajo, lo que determina que aquí el capitalista se halle interesado en el buen funcionamiento de esta "condición laboral".

En cuanto a las medidas de primeros auxilios, en las 28 empresas se declaró que existía un botiquín de primeros auxilios atendido por una enfermera, mientras que sólo en dos empresas se contaba además con la asistencia de un médico. Vemos más adelante lo insuficiente que resultan estos "servicios médicos" frente a las enfermedades de trabajo características de esta industria.

Interrogadas sobre posibles "ventajas adicionales" en sus condiciones laborales, las obreras respondieron negativamente en un $66.66 \%$ de los ca- 
sos. En el $33.33 \%$ restante -concentrado significativamente en las empresas más grandes de la muestra se habló de ciertas ventajas, tales como "días festivos", "bebedores de agua electropura", "lockers para las pertenencias de las obreras", "hora social", "descanso adicional de 10 minutos" y por último que "prestan el jardín para las fiestas particulares de las obreras". 6

Frente a estas magras ventajas, resalta la contundente declaración de una obrera, que como respuesta a la pregunta sobre sus condiciones de trabajo, contestó lisa y llanamente: "Trabajo y vida rutinaria".

\section{Alimentación durante la jornada laboral}

Existen tres posibilidades de alimentación durante la jornada laboral: se come en la empresa, se compra en los puestos cercanos a la planta, o se trae la comida de la casa.

Las empresas electrónicas encuestadas generalmente cuentan con comedor, aunque en cuatro de ellas no lo hay. Aunque en principio puede considerarse que el comedor en la empresa es indicador de "buenas condiciones" pues se considera una prestación a las trabajadoras, hay que tener en cuenta que de alguna manera esto también implica una situación favorable para la empresa, en tanto que permite que se pierda menos tiempo de trabajo efectivo. De hecho, algunas trabajadorás opinan que preferirían comer fuera, pero que a veces no les da tiempo para salir.

Las opiniones de los trabajadores acerca de la calidad de la comida que ahí se les da son muy variables, quizá dependiendo de los gustos y los hábitos de alimentación que ellos tienen, de manera que, aún tratándose de la misma empresa, hay quien encuentra la comida "buena", "mala", y "regtular". En todo caso las opiniones más frecuentes son de que la comida es regular, en primer lugar, y “mala" en segundo.

Guisado, sopa y frijoles es lo que generalmente se vende al interior de la planta, aunque también se sirven tostadas, burritos, gorditas o hamburguesas. El precio del "plato" es más o menos variable representando entre el 10 y el $14 \%$ del salario mensual de la trabajadora.

Las quejas sobre la comida se dan en torno a cuestiones tales como la higiene del comedor y el trato de las personas que lo atienden: no pocas

\footnotetext{
$\overline{6}$ Un aspecto de las condiciones de trabajo no abordado en la encuesta es el del ruido producido por las máquinas empleadas en algunas áreas de la producción. Sin embargo, en las entrevistas abiertas algunas obreras se refirieron a esté aspecto. En abril de 1977, la Secretaría de Salubridad y Asistencia realizó visitas en algunas de las maquiladoras más importantes, encontrando en la RCA: "mucho ruido mayor que el soportable y en el ambiente hay residuos nocivos para la salud". Se levantó un acta, ordenando a la empresa instalar el equipo adecuado.
} 
veces se quejan de que éstas "sirven primero a sus amigas". Aunque esto parecería un hecho trivial, su importancia se explica si se considera que el tiempo para comer es absolutamente limitado.

Aunque en el parque industrial Bermúdez hay una cafetería de autoservicio permanente, los más frecuentados son los puestos ambulantes que se instalan cerca de las fábricas. Se trata de "combis" o camionetas viejas que una vez instaladas, extienden una lona pequeña, en ocasiones ponen incluso mesas y sillas, y desde ahí atienden a las trabajadoras. Más que comida formal expenden burritos, tostadas, flautas, quesadillas y refrescos. Cuando venden "platos completos" (sopa, guisado y frijoles) son más caros que en la empresa, pero como se pueden comprar cosas sueltas, como quesadillas, o burros, se considera que es más barato que comer en la planta. Los burros (tacos) costaban en $1981, \$ 8.00$, cuando la comida en el comedor costaba alrededor de $\$ 28.00$.

En tanto que las condiciones de higiene dejan mucho qué desear y los precios son relativamente altos, podría pensarse que la comida trafda de la casa sería una mejor opción. No obstante, no son muchas las trabajadoras que en la fábrica comen alimentos preparados en casa. Algunas trabajadoras comentan que "no hay dónde calentar la comida", lo cual es evidentemente un inconveniente, pero también significa un problema más el tener que preparar la comida para llevar, especialmente si el horario de entrada es a las 6.45 de la mañana. El transporte también implica esta posibilidad, las "ruteras" siempre vienen llenas, por lo que parece preferible el tratar de "ahorrarse un bulto".

\section{Dotación de equipo de trabajo}

En dos de las empresas encuestadas no se dieron datos a este respecto $(7.14 \%)$; en $4(14.28 \%)$, se declaró que solamente se les proporcionaba a las obreras la bata y los guantes o protectores para los dedos ("dedales"). En 6 empresas $(21.42 \%)$, se les proporcionaba alguna combinación de estos tres elementos: lentes, bata y guantes; en 16 empresas se proporcionaban tres o cuatro elementos del equipo: lentes, bata, guantes, tape (cinta de aislar, para forrarse los dedos), cubrebocas, careta y gorro $(57.14 \%$ ).

Sin embargo, en las observaciones hechas por las obreras al respecto, en cuatro empresas declararon no usar los lentes de protección, porque "son lentes de aumento, que dan dolor de cabeza", "se nos cansa la vista", etc., a pesar de que las reprenden por ello. En dos empresas se quejaron de que "rara vez dan bata", y en otra, de que tampoco usan el cubrebocas, porque "les da vergüenza y además, no lo exigen, sólo el señor de Seguridad nos pide que lo usemos". En otra empresa se quejaron de que si pierden el equipo, tienen que pagarlo. 
Vemos así que no sólo existe problema en la dotación del equipo adecuado, sino que además existe escasa formación e información del personal sobre la necesidad y utilidad de emplearlo. En las entrevistas personales, sin embargo, las obreras nos dieron la clave para comprender esta aparente "indiferencia" ante su propia seguridad: no usan los guantes, lentes, etc., porque les hacen más difícil alcanzar los altos estándares de producción que se les exigen ("son estorbosos"). En todo caso, parece ser imprescindible pugnar por la valoración de los estándares en torno al mínimo posible utilizando el equipo idóneo. (Un ejemplo: los obreros que trabajan en las prensadoras dijeron trabajar solamente con protectores de hule en los dedos, porque los de acero -más seguros- "impiden trabajar rápido". Otras opiniones fueron: "deberíamos usar tape en los dedos, pero se hace más difícil el trabajo", "usamos la herramienta que nos dan, pero batallamos para que nos la den seguido". Finalmente, una de las jefes de línea respondió: "no cumplen con las reglas de seguridad, no todas usan el equipo, por desidia").

Son éstas, en general, las condiciones ambientales y de seguridad e higiene en que laboran las trabajadoras de la maquila electrónica. Pero no basta con ubicar las deficiencias a este respecto: falta analizar a qué ritmo, es decir, con qué intensidad se realiza el trabajo, para llegar a una aproximación más justa acerca del desgaste al que es sometida esta fuerza de trabajo. Abordamos este aspecto a continuación.

\section{Ritmos de trabajo}

Es este un aspecto central dentro de las condiciones de trabajo en las maquiladoras. Para "seguir vivas", estas empresas necesitan contar con niveles de "productividad" de las obreras muy altos y en constante ascenso. A pesar de que sería necesario efectuar un análisis del proceso de trabajo como tal, y a partir de éste calificar los ritmos de trabajo, nosotros solamente contamos con las impresiones de las trabajadoras acerca de los ritmos de trabajo impuestos por las empresas.

En las 28 empresas analizadas, se reportaron 54 diferentes opiniones acerca del ritmo de trabajo, de acuerdo con las distintas ubicaciones dentro del proceso de trabajo, así como de la experiencia particular y apreciación personal de las trabajadoras. Se calificó así el ritmo de trabajo como bueno (en once empresas), regular (en veinte), pesado (en trece) y muy pesado (en nueve). En una empresa no se respondió a esta pregunta.

Resumiendo, en el $20.3 \%$ de los casos distintos, se opinó que el ritmo de trabajo era bueno; en el $37 \%$ se le consideró regular; en el $24 \%$ fue calificado como pesado, y en el $16.6 \%$, como muy pesado. El $1.8 \%$ no respondió. De esta manera, el ritmo de trabajo se calificô como bueno o regular, en el $57.3 \%$ de los casos, y como pesado o muy pesado, en el $40.6 \%$. 
Ahora bien, al analizar las especificaciones acerca de los ritmos de producción, encontramos que de 110 obreras entrevistadas, 80 dieron explicaciones sobre su clasificación del ritmo de trabajo. En ellas, la calificación de regular daba cuenta de un ritmo no pesado, variable, o inclusive pesado.

En síntesis, los motivos para considerar bueno el ritmo de trabajo se centraron en torno a la escasa dificultad del trabajo, a que no existiera mucha presión para obtener el estándar, y a la posibilidad de variar de posición a lo largo de la jornada laboral.

El trabajo calificado como de ritmo regular lo fue por no implicar un estándar muy alto, o un alto grado de dificultad.

Las razones para considerar al ritmo de tzabajo como pesado se dieron en torno a estar en una sola posición durante las 8 o 9 horas de la jornada laboral, por lo alto de las estándares de producción exigidos, por las dificultades presentadas por algunos modelos o materiales, por los aumentos súbitos en los estándares o en el ritmo de la banda, o por el desgaste de la vista.

El ritmo de trabajo se calificó como muy pesado, por las mismas razones que en el caso anterior, aunque más extrremas. Solamente se agregó el esperar que las obreras cumplan con los estándares en cualquier línea, aun si no tiene experiencia alguna, y el incrementar los estándares arbitrariamente, sin considerar los tiempos reales factibles para cada operación. Las obreras que tuvieron la opinión de que su trabajo era muy pesado, plantearon inclusive la idea de que era un trabajo propio para los hombres.

Es de resaltarse también que resultan altamente indeseables para las obreras, los cambios bruscos en el ritmo de trabajo.

Las condiciones ambientales y de seguridad e higiene, así como los altos niveles de intensidad del trabajo arriba descritos, tienen que reflejarse, necesariamente, en los niveles de accidentalidad y en los padecimientos resultado de la actividad laboral. Tenemos así que, a pesar de las repetidas declaraciones de funcionarios del IMSS y de otras dependencias oficiales en cuanto a que los altos niveles de accidentalidad laboral en Ciudad Juárez no se deben a las condiciones de trabajo en la industria maquiladora, a partir de 1978 se intensifican las campañas del IMSS para mejorar las condiciones de trabajo en la industria maquiladora, a través de la formación de las Comisiones Mixtas de Seguridad e Higiene, visitas esporádicas a las fábricas, etc. Este interés en este rubro se explica claramente, por el aumento vertiginoso de los gastos realizados por el IMSS a causa de incapacidades otorgadas por accidentes laborales. Las obreras entrevistadas, por su parte, tenían 'clara con- 
ciencia de la serie de riesgos y accidentes más comunes dentro de las maquiladoras de tipo electrónico. Veamos.

\section{Accidentes de trabajo}

De las 28 empresas encuestadas, en 3 no se dieron datos sobre accidentes de trabajo (10.7\%). De las 25 restantes, los accidentes de trabajo reportados son los siguientes:

1) Machucones de dedos, con las remachadoras y prensadoras; se engrapan los dedos o se vuelan las uñas, en 19 empresas (67.85\%).

2) Cortaduras en dedos y manos, por máquinas, material o navajas (empleadas para quitar el material sobrante), pinchaduras con el alambre (18 empresas, $64.28 \%$ ).

3) Quemaduras en manos, con el cautín (11 empresas, $39.28 \%$ ).

4) Fracturas de dedos ( 3 empresas, $10.71 \%$ ).

5) Rebaba, soldadura o terminales en los ojos ( 9 empresas, $32.14 \%$ ).

6) Caídas, en 3 empresas ( $17.85 \%$ ).

7) Mutilaciones ( 5 empresas, $17.85 \%$ ).

8) El cabello se agarra en las máquinas ( 1 empresa, $3.57 \%$ ).

9) Se caen objetos pesados en los pies, y se "mochan" los dedos (una empresa, $3.57 \%)$.

10) Defunciones por quemaduras, en una empresa ( $3.57 \%)$.

En dos casos (jefa de línea e inspectora de calidad), se aclaró que los accidentes ocurrían "por el mal manejo de la herramienta, y por distracciones, o por descuido del trabajador"; en otros, se aclaró que ocurren "por falta de precaución de las muchachas, y a propósito, para no ir a trabajar", o que ocurren "a las que no tienen práctica". Sólo en el caso de las dos obreras muertas por quemaduras, se declaró que el accidente ocurrió "por negligencia de la empresa".

Vemos pues que constantemente existen en las maquiladoras de tipo electrónico una serie de accidentes, sobre todo en manos y ojos, que inclusive llegan a inutilizar a las obreras. Estos accidentes parecen estar ligados al uso insuficiente del equipo de trabajo adecuado (guantes, lentes protectores, etc.), que, como nos informaron las obreras, se debe a la dotación insuficiente de equipo por parte de la empresa, y a la incompatibilidad de su uso con los altos y crecientes estándares de producción exigidos. (Otra causa, poco explicada por las obreras en nuestra encuesta, pero captada en las entrevistas abiertas, son las alergias causadas por el equipo protector. Ün ejemplo son los cubrebocas de fibra de vidrio). 


\section{Enfermedades laborales}

A pesar de la opinión de las autoridades del IMSS, de que hasta 1980 (fecha en que se hicieron declaraciones en el diario El Fronterizo a este respecto) no se había registrado ningún caso de enfermedad profesional en ninguna de las industrias de maquila de Ciudad Juárez, las obreras encuestadas coincidieron en señalar como enfermedades o padecimientos producidos por el tipo de trabajo realizado, una significativa gama, que analizamos a continuación.

De las 28 empresas encuestadas, en $22(78.57 \%)$ se dieron datos sobre enfermedades que las obreras consideraron eran producto del proceso laboral. Significativamente, varias inspectoras de calidad y jefes de grupo coincidięron en afirmar que no existía "ninguna enfermedad de trabajo". Sin embargo, a partir de los datos de la muestra, nos encontramos con que el trabajo en las maquiladoras electrónicas produce, a juicio de las obreras, los siguientes padecimientos: 1 ) enfermedades de la vista (alérgicas, $35.71 \%$; cansancio de la vista, $21.42 \%$ ), 2) enfermedades de las vías respiratorias (alérgicas, $32.14 \%$; resfriados, bronquitis, amigdalitis, $10.71 \%$ ), 3) enfermedades del aparato digestivo (gastritis, $17.85 \%$; otras enfermedades gastrointestinales, $14.28 \%$ ), 4) enfermedades de la piel (alérgicas, $21.42 \%$ ), 5 ) reumas en las manos $(7.14 \%$ ), 6) cansancio (de la espalda, dolores de riñones, $25 \%$; desmayos, $14.28 \%$, cansancio en general, $3.57 \%$; cansancio de los pies, $3.57 \%)$, 7) dolor de cabeza $(21.42 \%)$.

Destacan los padecimientos alérgicos que atacan a ojos, vías respiratorias y piel, debidos a las substancias y materiales con los que se trabaja. Por otro lado, la tensión producida por las altas exigencias de productividad genera cansancio general (desmayos, inclusive) y dolores de cabeza, en tanto que el esfuerzo visual produce cansancio de la vista, y las posiciones corporales dan lugar a cansancio y dolores de espalda, de riñones y de pies.

Los cambios de temperatura dan lugar a frecuentes enfermedades de las vías respiratorias, y los cambios de temperatura en las manos producen reumas e inclusive, de acuerdo con la información de las entrevistas libres, artritis.

Finalmente, el comer de prisa (recuérdese que las obreras cuentan con 10 minutos para desayunar, y 30 minutos para comer, los cuales se reducen aún más si descontamos el tiempo que tardan en salir a la calle o al comedor de la empresa) y el tomar alimentos antihigiénicos y difíciles de digerir, producen frecuentes padecimientos del aparato digestivo (que quizás tengan también una relación con la tensión nerviosa propia del estilo de vida del trabajo en maquiladora). 


\section{Otras enfermedades}

Las respuestas a la pregunta acerca de cuáles eran las enfermedades más comunes en tre las obreras, además de las enfermedades de trabajo, coincidieron en ser: 1) gripe y otras enfermedades respiratorias ( $57.14 \%$ ), en 16 empresas; 2 ) diarreas, gastritis, cólicos, en 10 empresas $(35.7 \%) ; 3$ ) anemia, en una empresa ( $3.57 \%$ ); embarazos, en 3 empresas ( $10.71 \%$ ).

La presencia constante de enfermedades respiratorias y digestivas es consecuencia de las características climáticas de Ciudad Juárez, y de las condiciones de vida de las colonias populares en las cuales habitan las obreras. Los embarazos frecuentes corresponden a la fecundidad de los grupos de edades a los que pertenecen las trabajadoras de maquila electrónica.

A la luz de estos datos, recordamos la concepción de Giovanni Berlinguer: el principal agente patógeno para la salud obrera es el capital. ${ }^{7}$

Prevención de los accidentes y enfermedades de trabajo por el IMSS, el sindicato y la empresa

En este punto, resalta la ineficiencia de los programas desarrollados por el IMSS y las propias empresas en torno a la prevención de accidentes y enfermedades laborales, a juicio de las obreras entrevistadas. En dos de las empresas encuestadas no se dio información a este respecto. De las 26 restantes encontramos diversas respuestas, dentro de una misma empresa, que se resumen de la siguiente forma: un $60.71 \%$ de las empresas no hace nada para prevenir accidentes y enfermedades de trabajo, aunque en el $46.42 \%$ de las empresas hubieron obreras que contestaron que la empresa previene accidentes y enfermedades, proporcionándoles el equipo adecuado para cada trabajo. En un $25 \%$ de las empresas, se realizaban campañas sobre prevención de riesgos y accidentes, así como capacitación al respecto. Otras actividades realizadas en menor proporción de empresas, son: avisos, posters, memorandums de prevención, buscar nuevos métodos productivos y nuevos materiales; mantener adecuadamente la maquinaria; estabiecer y difundir las medidas de seguridad; proporcionar servicio de enfermería (éste existe en todas las empresas encuestadas, pero sólo en unas cuantas las obreras lo consideraron como una medida de prevención).

Del IMSS, la opinión fue de que no hace nada para prevenir accidentes y enfermedades laborales, en el $57.14 \%$ de las empresas; en un $32.14 \%$,

7 Otro aspecto que debe ser mencionado como parte de las condiciones de trabajo en estas empresas, es el de la falta de seguridad, tanto en los parques industriales (atropellamientos, robos, violaciones, etc.), como dentro de las mismas empresas (incendios, estallamiento de tanques de gas, contaminación por sustancias derramadas e incluso avisos de bombas). 
que realiza campañas de vacunación; que proporciona asistencia médica, en el $25 \%$; en el $17.85 \%$, que da las incapacidades,y en una empresa, que establece aumentos progresivos de las cuotas patronales, de acuerdo con el número de accidentes ocurridos en la empresa.

De las trabajadoras, las acciones reportadas son el poner mayor atención y tener más precaución al trabajar (en el 46.42\% de las empresas); usar el equipo de seguridad y cumplir con las normas (42.85\%); acudir al IMSS $(14.28 \%) \mathrm{y}$, en menor proporción, quejarse con la empresa, exigir el equipo adecuado, llevar sus propias medicinas, acudir a la enfermería de la empresa y, en una fábrica, hacer huelga. Aún así, en el $50 \%$ de las empresas se respondió que no hacían nada.

La acción sindical sólo estuvo presente en el $21.42 \%$ de las empresas encuestadas, pues el 78.57 restante carecía de organización sindical. La opinión de las trabajadoras fue, en las 6 empresas sindicalizadas, que el sindicato no hacía nada respecto a la prevención de accidentes y enfermedades laborales, aunque en una muy baja proporción se opinó que presionaba a la empresa para que proporcionara a las obreras la herramienta adecuada, el hacer campañas y juntas, y el intervenir para que se atienda a la obrera lesionada. Una obrera anotó: "Nada. A esos les da lo mismo. Siempre están fuera de la fábrica".

Resalta aquí el hecho de que ninguna de las obreras hablase para nada de la formación de las Comisiones Mixtas de Seguridad e Higiene, a pesar del supuesto éxito de la campaña del IMSS en torno a este aspecto, reflejada en las declaraciones del líder de la CRT, tercera central sindical "en activo" en las maquiladoras en Ciudad Juárez. Según él (10 de agosto de 1980): "Con motivo de la integración de las comisiones mixtas de seguridad e higiene, en la industria maquiladora, los accidentes de trabajo se han reducido en más de un $60 \%(\ldots)$ anteriormente se registró un número considerable de accidentes, algunos de gravedad (...) Gracias a las comisiones, las diferentes empresas de maquila tuvieron que adquirir el equipo necesario y adoptar las medidas de seguridad requeridas para evitar accidentes de trabajo ( . . . )".

\section{Sindicalismo y otras formas de resistencia obrera}

El panorama anteriormente expuesto de las condiciones laborales en las industrias maquiladoras electrónicas de Ciudad Juárez, nos muestra la base sobre la cual ocurren las manifestaciones espontáneas de resistencia obrera, los avances del sindicalismo de la CROC, la CTM y la CRT, así como los brotes de sindicalismo independiente, o de democratización de los sindicatos oficiales. 
Este aspecto, enmarcado en el contexto del desarrollo del proletariado propiamente industrial en Ciudad Juárez, de su importancia estratégica dentro de las bases sociales del sindicalismo oficial (recuérdese que Ciudad Juárez era, hasta la implantación de las maquiladoras, una ciudad esencialmente "de servicios"), etc., merece un estudio serio. Por ahora, simplemente plantearemos los resultados obtenidos en nuestra encuesta, en torno a la opinión de las obreras respecto de la acción sindical, puesto que las formas de resistencia espontánea fueron detectadas de manera somera ("San Lunes", tortuguismo, etc.). ${ }^{8}$

De las empresas encuestadas, seis estaban sindicalizadas, perteneciendo dos a la CROC y 4 a la CTM (2,268 y 7,354 obreros, respectivamente). Su contribución a solucionar los problemas de condiciones de trabajo fue descrita de la siguiente forma:

a) Salarios, De las 18 obreras que respondieron esta sección de la encuesta, 12 respondieron que el sindicato no hacía nada para mejorar su situación salarial. Algunas observaciones fueron: "hacen lo que les conviene", "sólo hace lo que quiere la empresa", "nada, siempre dicen que están muy ocupados". Las seis restantes consideraron que la acción sindical a este respecto consistía en hablar con la empresa, tratar que se cumpla el contrato colectivo de trabajo, e inclusive una obrera planteó que no existía ningún problema a este respecto, puesto que cada año aumentaban los salarios.

b) Condiciones de trabajo. A este respecto, 12 obreras consideraron que el sindicato no hacía nada para mejorar, quejándose una de ellas de que el sindicato no intervenía con la empresa para que las dejaran salir a comer fuera. Las razones para plantear que el sindicato sí contribuía a solucionar este tipo de problemas, fueron, en las seis obreras restantes, que hablaba con el ingeniero para "solucionar pequeños problemas", que "se preocupa de que todo esté bien", "habla con la empresa", y que ya había mayor seguridad, a causa de su intervención.

c) Contratación. Catorce de las obreras dijeron no estar conformes con la acción sindical a este respecto, con observaciones como que "el sindicato contrata sólo a las personas que quiere", "compadrazgos, favoritismo". Las cuatro obreras restantes plantearon que el sindicato sí intervenía en la contratación, por el hecho de que era él quien contrataba.

8 Asi, en febrero de 1982 en El Fronterizo aparecieron declaraciones de un funcionario del IMSS, en las cuales se "quejaba" de que en tanto de martes a domingo asistían 1500 derechohabientes en busca de asistencia médica, el dia lunes aumentaba esa cifra hasta 2300 personas. 
d) Dotación de equipo de trabajo. Diecisiete obreras negaron que existiera alguna intervención sindical respecto a la dotación del equipo de trabajo por la empresa, a pesar de las presiones ejercidas por las obreras, en una de las empresas. Solamente una obrera consideró que el sindicato presionaba a la empresa para lograr una dotación adecuada de equipo.

e) Despidos. Dieciseis trabajadoras plantearon que el sindicato no hacía nada respecto a los despidos, observando dos de ellas que "no hace nada a nuestro favor", y que "van, pero no creo que arreglen nada". Solamente dos obreras respondieron afirmativamente a esta pregunta, una de ellas anotando que "a veces" sí lograba algo positivo el sindicato.

f) Cuotas sindicales. Todas las obreras aportaban cuota sindical, que iba de $\$ 4.00$ a $\$ 20.00$, siendo lo más común el pagar $\$ 10.00$.

g) Asistencia a reuniones sindicales. Doce obreras declararon no asistir nunca a las reuniones sindicales, con argumentos del tipo de "no, porque son puros chismes", o "no se respetan los reglamentos para las elecciones de delegado sindical". Las seis restantes asistían, dos de ellas irregularmente. Lo más común es que las reuniones sindicales se efectúen una vez al mes, aunque en una de las empresas se informó que se hacían frecuentes juntas del sindicato con el ingeniero, en cada una de las líneas de producción.

Tenemos pues, que si bien aparentemente las obreras de maquila parecen tener una actitud francamente "anti-sindicalista", que se manifiesta al platicar con ellas, con expresiones como ¿"sindicato? no, gracias", "son puros ladrones", etc., en las empresas ya sindicalizadas se tiene conciencia bastante generalizada de que, habiendo cauces legales y organizativos para la intervención sindical en favor de las trabajadoras, esto no ocurre debido al carácter anti-democrático y pro-patronal de las organizaciones existentes. 